\title{
Management of Lateral Elbow Pain with Glucopuncture
}

\author{
Jan Kersschot* \\ Private Practice, Belgium
}

*Corresponding author: Jan Kersschot, Private Practice, Belgium.

\begin{abstract}
Lateral elbow pain is a common condition which is usually described as a musculotendinous degenerative disorder of the extensor origin at the lateral epicondyle. As a result of its high prevalence, knowledge of its clinical presentation and tailor-made management is essential. Many patients are looking for safe and affordable injection techniques which can accelerate their recovery. Recently, local glucose 5\%injections have received more attention when it comes to treating lateral elbow pain. Controlled clinical studies are required to compare the outcome of local glucose $5 \%$ injections with cortisone injections or platelet rich plasma injections.
\end{abstract}

Keywords: Lateral elbow pain; Glucopuncture; Tennis Elbow; Prolotherapy; Trigger point.

\section{Introduction}

Lateral elbow pain is a common condition that affects patients between 35 and 55 years of age [1]. It is usually described as a musculotendinous disorder of the extensor origin at the lateral humeral epicondyle, but the pain may also have a muscular, tendineous or ligamentous origin (see 2). As a result of its high prevalence, knowledge of its clinical presentation and up-to-date management strategies are essential.

Lateral epicondylitis is a common overuse injury affecting approximately 1 to 3 percent of the population [2]. The typical symptoms include elbow pain with wrist extension and weakened grip strength. The cause is thought to be repetitive activities involving wrist extension and supination. The pain is usually located at or near to the lateral epicondyle. This clinical picture is typically described as "tennis elbow". Some patients with lateral elbow pain, however, have a different clinical picture than tennis elbow and need a different approach.

\section{Diagnosis of Lateral Elbow Pain}

\section{Introduction}

The diagnosis is made through history, physical examination, and imaging (X-rays, ultrasound, MRI). The history should make clear if the elbow pain started suddenly after a traumatic event, or gradually over days, weeks, or months. In the first situation, one should look for fractures, dislocations, ligament injuries, or pain originating from periost lesions (e.g., a direct blow), or a combination of those (such as in a car accident). In the second situation, one might consider that the pain is musculotendinous in origin. Then one should check whether the patient suffers from for myofascial pain [3], chronic tendinopathy of the common extensor tendon (CET), enthesopathy of the CET at the lateral epicondyle, or a combination of those.

\section{Ligamentous Lateral Elbow Pain}

When dealing with post traumatic lateral elbow pain, X-Rays 
are used to exclude bone fractures. Such patients with fracturesare immediately referred to an orthopedic surgeon specialized in elbow traumatology [4]. Posttraumatic ligament lesions may lead to elbow instability and dislocation, and mightrequire surgical intervention as well $[5,6]$.

The lateral collateral ligament (LCL) is a capsuloligamentous structure critical in stabilizing the ulnohumeral and radiocapitellar articulations. Minor LCL lesions can be the cause of chronic pain in the lateral elbow and can be identified with precise palpation guided examination with comparisons made to the contralateral uninjured side. It is not always easy to identify which ligaments in the elbow joint are the actual origin of the patients' pain (e.g., radial collateral ligament, annular ligament). It is also a challenge to differentiate ligamentous pain from pain originating from the joint capsule with imaging, although it is said that lateral collateral ligament (LCL) injuries can be identified on MRI [7].

\section{Periosteal Elbow Pain}

Sometimes the patient pinpoints one particular sore point on the bone (e.g., at the lateral epicondyle itself or an inch above the lateral epicondyle). This pain may be the result of a direct trauma on the bone (e.g., someone hit a squash racket on that particular spot), but usually the patient will not recall such an event. This pain may originate from nerves exhibiting substance P-like immunoreactivity in the periosteum [8]. It is challenging to locate and inject such a sore point on the periosteum.

\section{Musculotendinous Elbow Pain}

Lateral elbow pain may also be musculotendinous in origin. This is usually the case when the pain started gradually after repetitive wrist extension and supination. Here there are three components which may lead to pain in the lateral elbow and forearm. The pain can be muscular (common extensor, brachioradialis), tendinous (e.g., common extensor tendon) or enthesopathic (e.g., enthesis of the common extensor on the elbow). Rigorous palpation may identify which tissues are involved, and where exactly the injections should be applied. The depth of injection is related to the amount of pressure one needs to apply to find the painful points in the affected tissue.

\section{Muscular Pain Secondary to Ligamentous Instability}

The lateral collateral ligaments are supported by a muscular component to provide stability to the joint. There are four muscles which can help in stabilizing the elbow joint, the supinator, common extensor, anconeus and brachialis. In case of LCL lesions, these muscles might try to compensate the instability in the elbow joint and as a result of that become stiff and painful. This is described as "muscular" elbow pain which is secondary to ligamentous lesions. It is a rather uncommon type of chronic lateral elbow pain.

\section{Management of Lateral Elbow Pain}

Lateral elbow pain is generally self-limiting, but in some patients, it may continue to cause persistent symptoms, which can be refractory to treatment [9]. Most patients improve with nonoperative measures, such as rest, ice, physical therapy, and injections. A small percentage of patients will require surgical release of the extensor carpi radialis brevis tendon [10,11]. Local corticosteroid injections are inexpensive but should be used with caution in the management of tennis elbow because of potential side effects and short-termbenefits [12]. Platelet Rich Plasma (PRP) injection might be considered for itslong-term effects [13]. In this article, the focus is on the application of Glucopuncture to manage lateral elbow pain.

\section{Definition of Glucopuncture}

Glucopuncture (GP) is an injection-based therapy for the management of a variety of non-rheumatic musculoskeletal conditions [14]. It consists of multiple local injections of G5W (Glucose 5\% in Water). Anecdotal evidence suggests that these injection shave a favorable effect on (1) pain modulation and (2) physiological repair mechanisms of damaged or inflamed tissues such as muscles, tendons, and ligaments. Glucose $5 \%$ (or dextrose $5 \%$ ) injections have been used for low back pain $[15,16]$, radicular low back pain [17], snapping scapula [18] and Achilles tendinopathy [19]. Although the mechanism of action of G5W injections is largely unknown, it is likely to be multi factorial. More research in this field is definitely required.

\section{Superficial Injections and Deep Injections}

There are two main injection techniques used in Glucopuncture, superficial injections and deep injections. Superficial injections (6.1) are given in the dermis or epidermis. These are applied for pain modulation. Deep injections (6.2) are applied in, for example, muscles, tendons, and ligaments. These are given for tissue repair.

\section{Application of Glucose 5\% Injections for Lateral Elbow Pain}

\section{Superficial Injections}

One starts with subcutaneous (SC) or intracutaneous (IC) injections in the zone of pain referral. Intracutaneous injections seem to have a better pain modulating effect than subcutaneous injections, but this needs to be further explored. SC and IC injections are remarkably simple, safe, and straightforward. The patient points out the tender area in the elbow and multiple injections with glucose $5 \%$ are subsequently given in that zone. Especially in acute phases, this technique can be sufficient to modulate pain. As a result, prescribing pain killers and anti-inflammatory medication can be reduced or avoided. The patient may report that the elbow pain is much better immediately after the injections. This is 
rather surprising, as no local anesthetics are added to the glucose. Unfortunately, this effect is short lived. To obtain lasting results, the sessions need to be repeated. Side effects are rare. Local bruising and dermatitis may occur, but both subside without treatment in about a week time.

\section{Deep Injections}

When dealing with chronic lateral elbow pain, the superficial injections in the skin will not be sufficient. One should also address pain points or trigger points found in muscles, tendons, ligaments and / or entheses. Because the strategy is not based on imaging but on clinical examination (pain points, trigger points), most of these injections can be described as palpation-guided injections. Side effects are rare in experienced hands. The injections can be given in muscles such as the common extensor or brachioradialis, or the lateral head of the triceps in case of referred myofascial pain $[20,21]$. One can also inject glucose $5 \%$ adjacent to tendons such as the common extensor tendon (CET). If tender points are found at the enthesis of the common extensor on the lateral epicondyle, injections are given in that particular area. In some rare cases, injections are given on pain points at the periost of the lateral epicondyle. As a rule of thumb, these injections are repeated on a weekly basis until clinical improvement is achieved.

\section{Conclusion}

Patients with lateral elbow pain should have access to treatment modalities which are safe, affordable, and effective. Several clinicians worldwide have experienced that glucose 5\% injections can be used as an alternative for corticosteroid or PRP injections. More research in this field is required to confirm such findings.

\section{Acknowledgement}

None.

\section{Conflicts of Interest}

No Conficts of interest.

\section{References}

1. Duncan J, Duncan R, Bansal S, Davenport D, Hacker (2019) A Lateral epicondylitis: the condition and current management strategies. $\mathrm{Br}$ J Hosp Med (Lond) 80(11): 647-651.

2. Kim YJ, Wood SM, Yoon AP, Howard JC, Yang LY, et al. (2021) Efficacy of Nonoperative Treatments for Lateral Epicondylitis: A Systematic Review and Meta-Analysis. Plast Reconstr Surg 147(1): 112-125.
3. Shmushkevich Y, Kalichman L (2013) Myofascial pain in lateral epicondylalgia: a review. J Bodyw Mov Ther 17(4): 434-439.

4. Kani KK, Chew FS (2019) Terrible triad injuries of the elbow. Emerg Radiol 26(3): 341-347.

5. Reichel LM, Milam GS, Sitton SE, Curry MC, Mehlhoff TL (2013) Elbow lateral collateral ligament injuries. J Hand Surg Am 38(1): 184-201.

6. Anakwenze OA, Kancherla VK, Iyengar J, Ahmad CS, Levine WN (2014) Posterolateral rotatory instability of the elbow. Am J Sports Med 42(2): 485-491.

7. Cha YK, Kim SJ, Park NH, Kim JY, Kim JH, et al. Magnetic resonance imaging of patients with lateral epicondylitis: Relationship between pain and severity of imaging features in elbow joints. Acta Orthop Traumatol Turc 53(5): 366-371.

8. Gronblad M, Liesi P, Korkala O, Karaharju E, Polak J (1984) Innervation of human bone periosteum by peptidergic nerves. Anat Rec 209(3): $297-$ 299.

9. Ahmad Z, Siddiqui N, Malik SS, Abdus-Samee M, Tytherleigh-Strong G, et al. (2013) Lateral epicondylitis: a review of pathology and management. Bone Joint J 95-B(9): 1158-1164.

10. Tosti R, Jennings J, Sewards JM (2013) Lateral epicondylitis of the elbow. Am J Med A 126(4): 357.e1-6.

11. Lenoir H, Mares O, Carlier Y Management of lateral epicondylitis. Orthop Traumatol Surg Res 105(8S): S241-S246.

12. Bisset L, Beller E, Jull G, Brooks P, Darnell R, et al. (2006) Mobilisation with movement and exercise, corticosteroid injection, or wait and see for tennis elbow: randomised trial. BMJ 333(7575): 939.

13. Mishra AK, Skrepnik NV, Edwards SG, Jones GL, Sampson S, et al. (2014) Efficacy of platelet-rich plasma for chronic tennis elbow: a double-blind, prospective, multicenter, randomized controlled trial of 230 patients. Am J Sports Med 42(2): 463-471.

14. Kersschot J (2021) Glucopuncture: Series of Regional Multiple Glucose 5\% Injections. Adv Complement Alt Med 6(2).

15. Lyftogt J (2008) Prolotherapy for recalcitrant lumbago. Aust Musculoskelet Med 13: 18-20

16. Maniquis-Smigel L, Reeves KD, Rosen JH, et al. (2017) Short term analgesic effects of $5 \%$ dextrose epidural injection for chronic low back pain. A randomized controlled trial. Anesth Pain Med 7: e42550.

17. Koroglu Ozlem, Orscelik Aydan, Karasimav Ozlem, Demir Yasin, Solmaz Ilker (2019) Is 5\% dextrose prolotherapy effective for radicular low back pain? Gulhane Medical Journal 61(3): 123-127.

18. Mansız-Kaplan B, Nacır B, Pervane-Vural S, Genc H (2020) Pain relief in a patient with snapping scapula after $5 \%$ dextrose injection. Turkish Journal of Physical Medicine and Rehabilitation 66(3): 368-369.

19. Lyftogt J (2007) Subcutaneous prolotherapy for Achilles tendinopathy. Aust Musculoskelet Med 12: 107-109.

20. Tantanatip A, Chang KV (2020) Myofascial Pain Syndrome. In: StatPearls [Internet]. Treasure Island (FL).

21. Hammi C, Schroeder JD, Yeung B (2020) Trigger Point Injection. In: StatPearls [Internet]. Treasure Island (FL). 